\title{
Surface morphology and corrosion resistance of electrodeposited composite coatings containing polyethylene or polythiophene in Ni-Mo base
}

\author{
J NIEDBALA \\ Institute of Materials Science, University of Silesia, 40-007 Katowice, ul. Bankowa 12, Poland \\ MS received 11 December 2009; revised 30 April 2010
}

\begin{abstract}
Ni-Mo $+\mathbf{P E}_{\mathrm{Ni}}$ and $\mathrm{Ni}-\mathrm{Mo}+\mathrm{PTh}$ composite coatings have been prepared by nickel-molybdenum deposition from a bath containing a suspension of $\mathrm{PE}_{\mathrm{Ni}}$ or $\mathrm{Th}$. These coatings were obtained at galvanostatic conditions, at a current density of $j_{\text {dep }}=-0.100 \mathrm{~A} \mathrm{~cm}^{-2}$ and temperature of $293 \mathrm{~K}$. A scanning electron microscope was used for surface morphology characterization of the coatings. The chemical composition of the coatings was determined by EDS. Electrochemical corrosion resistance investigations were carried out in $5 \mathrm{M} \mathrm{KOH}$, using potentiodynamic and electrochemical impedance spectroscopy (EIS) methods. On the basis of these investigations it was found, that the composite coatings containing thiophene are more corrosion resistant in alkaline solution than the $\mathrm{Ni}-\mathrm{Mo}+\mathrm{PE}_{\mathrm{Ni}}$ coatings. This is caused by presence of the polymer on the coatings surface and decrease of corrosion active surface area of the coatings.
\end{abstract}

Keywords. Ni-Mo + PTh composite coatings; Ni-Mo + PE composite coatings; Ni-Mo coatings; corrosion resistance.

\section{Introduction}

The composite layer with a polymer may be obtained as a result of: (i) simultaneous deposition of metallic matrix and electropolymerization based on the reduction of monomer, (ii) the cathodic deposition process of the metallic matrix alternatively with anodic electropolymerization based on the monomer oxidation processes and (iii) direct building inactive polymer particles during cathodic matrix deposition (Bozzini and Sgura 2006). The composite layers containing a polymer embedded into metallic matrix were prepared by electrodeposition in a galvanic bath and used for different purposes (Hamid and Ghayad 2002; Wang et al 2004; Bozzini and Sgura 2006; Niedbala et al 2008). It was found that this addition improved some properties of the obtained layers, e.g. the nickel layers exhibited higher microhardness compared to those prepared using pure nickel (Hamid and Ghayad 2002).

Nickel alloys with molybdenum are used as electrode materials and characterised by catalytic properties during various electrochemical processes (Landolt et al 1999; Karimi-Shervedani and Lasia 1998, Niedbala 2006). The most frequently used modifiers of the alloy coatings are metal powders or oxides (Niedbala et al 2004).

(jolanta.niedbala@us.edu.pl)
The polymer built-in into the metallic matrix changed the surface morphology of the layer obtained in the electrolytic process. The developed surface of the electrolytic layer may be smoothed after polymer building (most often in pores). The polymer particles located on the surface can change surface density of the electrons in the metallic matrix (Niedbala et al 2008).

This study was undertaken to obtain the nickelmolybdenum coatings, containing polythiophene or polyethylene as additional organic component. For determination of the influence of the polymer in composite coatings on the corrosion resistance, they were compared with nickel-molybdenum coatings. The purpose of this research was to evaluate $\mathrm{Ni}-\mathrm{Mo}+\mathrm{PE}, \mathrm{Ni}-\mathrm{Mo}+\mathrm{PTh}$ and Ni-Mo coatings as electrode materials for alkalinesolution corrosion resistance, with respect to their surface morphology and composition.

\section{Experimental}

The Ni-Mo + PE composite layers were prepared from electroplating bath with the following composition $\left(\mathrm{mol} \mathrm{dm}^{-3}\right.$ ) (Niedbala et al 2008): $\mathrm{Na}_{2} \mathrm{MoO}_{4} 0 \cdot 035 ; \mathrm{NiSO}_{4}$ $0.75 ; \mathrm{C}_{6} \mathrm{H}_{5} \mathrm{Na}_{3} \mathrm{O}_{7} \cdot 0 \cdot 45$, in which $10 \mathrm{~g} \cdot \mathrm{dm}^{-3}$ of polyethylene powder was dispersed (PE, size $7-15 \mu \mathrm{m} ; d=0.91-$ $0.925 \mathrm{~g} \mathrm{~cm}^{-3}$ ). The powder was preliminarily chemically nickel plated $\left(\mathrm{PE}_{\mathrm{Ni}}\right)$ in a solution containing $\mathrm{NiSO}_{4}$ and $\mathrm{NaH}_{2} \mathrm{PO}_{2}$, according to generally accepted procedure. 
Electrolytical layers with polythiophene (PTh) were prepared from mixture of two solutions: (I) with the following composition $\left(\mathrm{mol} / \mathrm{dm}^{3}\right)$ (Niedbala et al 2006): $\mathrm{Na}_{2} \mathrm{MoO}_{4} 0.035 ; \mathrm{NiSO}_{4} 0.75 ; \mathrm{C}_{6} \mathrm{H}_{5} \mathrm{Na}_{3} \mathrm{O}_{7.0} .45, \mathrm{pH} 6.0-$ 7.0 and (II) containing $\left(\mathrm{mol} / \mathrm{dm}^{3}\right) \mathrm{HClO}_{4} 0.025$; thiophene (Th) $\mathrm{C}_{4} \mathrm{H}_{4} \mathrm{~S}$ (99.9\% Aldrich) 0.1. The solution was prepared using reagents of analytical purity (POCh Gliwice) and twice distilled water. All components of (I) bath were dissolved separately in a small volume of distilled water. Ni-Mo + PTh coatings were electrodeposited from a mixture containing solutions (I) and (II) in the proportion $3: 1$. Thiophene was freshly distilled and dissolved in $\mathrm{HClO}_{4}$ solution.

The coatings were deposited on a steel substrate ( $\mathrm{St} 3 \mathrm{~S}$ steel, $4 \mathrm{~cm}^{2}$ plate), preliminarily polished and then etched chemically in $\mathrm{HCl}$ solution (v/v $1: 1)$ for $5 \mathrm{~min}$ and electrochemically in a $0.8 \mathrm{~mol} \mathrm{dm}^{-3}$ solution of sodium gluconate $\left(\mathrm{C}_{6} \mathrm{H}_{11} \mathrm{NaO}_{7}\right)$. The other side of a plate was covered with non-conducting, chemically resistant adhesive. During deposition process the bath was mechanically stirred (250 rev/min). A platinum mesh served as an auxiliary electrode. Temperature of the bath was $298 \mathrm{~K}$, and pH 6-7. Coatings were obtained at galvanostatic conditions, at a current density of $j_{\text {dep }}=-0.100 \mathrm{~A} \mathrm{~cm}^{-2}$ and temperature of $293 \mathrm{~K}$. During $\mathrm{Ni}-\mathrm{Mo}+\mathrm{PTh}$ coatings deposition two processes occur simultaneously: (i) the $\mathrm{Ni}$ with Mo inductive electrodepositing process, (ii) the electropolymerization/electrodeposition process of polymer. $\mathrm{Ni}-\mathrm{Mo}+\mathrm{PE}$ production proceeded simultaneously with Ni-Mo deposition and PE incorporation.

Surface morphology of the coatings was examined using JSM-648 electron microscope, and surface images were recorded at the accelerating voltage of $15 \mathrm{kV}$. For the assessment of polyethylene content in a coating the Micro-Scan computer program was used and a system for morphometric measurements composed of the NIKKON SMZ-2T stereoscopic microscope and Panasonic GTKR22E type colour camera. The contents of $\mathrm{Ni}, \mathrm{Mo}, \mathrm{C}$ and $\mathrm{S}$ in the coatings were determined by the energy dispersive X-ray spectroscopy (EDS) method.

Electrochemical corrosion resistance investigations were conducted on the coatings in a three-electrode cell, using potentiodynamic and electrochemical impedance spectroscopy methods. These measurements were carried out in a $5 \mathrm{M} \mathrm{KOH}$ solution, using an $\mathrm{Autolab}^{\circledR /}$ PGSTST20 (Eco Chemie B.V. the Netherlands) electrochemical system. The auxiliary electrode was a platinum mesh and the reference electrode was $\mathrm{Hg} / \mathrm{HgO} / 6 \mathrm{M} \mathrm{KOH}$ type. Open circuit potentials of the coatings were determined using a range of $\pm 0.150 \mathrm{~V}$ from the determined value and the recorded potentiodynamic curve with rate $v=0.050 \mathrm{~V} \mathrm{~min}^{-1}$. Values of the corrosion potentials and the corrosion currents were determined by the Stern method. The electrochemical impedance measurements were performed at the corrosion potential. In these measurements the amplitude of the ac signal was $0.005 \mathrm{~V}$. A frequency range from $10 \mathrm{kHz}$ to $0 \cdot 1 \mathrm{~Hz}$ was covered with 10 points per decade. All electrochemical investigations were made at $293 \mathrm{~K}$.

\section{Results and discussion}

The obtained composite coatings with polymer adhered well to the substrate, and they were grey, matt and velvety, with visible particles of the embedded polymer. For $\mathrm{Ni}-\mathrm{Mo}+\mathrm{PE}_{\mathrm{Ni}}$ coatings, polymer was uniformly covered with nickel-molybdenum matrix (figure 1a). The results of surface morphology investigation of $\mathrm{Ni}-$ $\mathrm{Mo}+\mathrm{PTh}$ show that on the nickel-molybdenum surface the smaller polythiophene grains are clearly visible (figure 1b). The polymer particles in the obtained layers are uniformly embedded into the Ni-Mo matrix. Clearly configured polymers grains are embedded onto the composite matrix. It may be assumed, that the nickel with molybdenum inductive electrodepositing process and the electropolymerization/electrodeposition process of polymer proceeded independently, without influencing one another. It was found that the structure of the Ni-Mo layers (figure 1c) is relatively regular and is of an island character. When polythiophene is embedded into the Ni-Mo matrix, its structure changes and is no more an island. The presence of the $\mathrm{PE}_{\mathrm{Ni}}$ particles built into the pores causes the rough and developed surface of electrodeposited $\mathrm{Ni}-\mathrm{Mo}$ matrix become more smooth. Morphometric measurements made to determine polyethylene content in the $\mathrm{Ni}-$ $\mathrm{Mo}+\mathrm{PE}_{\mathrm{Ni}}$ coating showed that it was $24.2 \pm 1.2 \%$ (table 1). The chemical analysis was determined by EDS method. The composite coatings with polyethylene determined $\mathrm{Ni}, \mathrm{Mo}$ in the $\mathrm{Ni}-\mathrm{Mo}$ matrix. In the $\mathrm{Ni}-$ $\mathrm{Mo}+\mathrm{PTh}$ coatings, $\mathrm{Ni}, \mathrm{Mo}, \mathrm{C}$ and $\mathrm{S}$ were determined. In $\mathrm{Ni}-\mathrm{Mo}+\mathrm{PE}_{\mathrm{Ni}}$ coating the Ni content was $74 \cdot 2 \pm 2 \cdot 2 \%$ and $\mathrm{Mo} 25 \cdot 8 \%$. In the $\mathrm{Ni}-\mathrm{Mo}+\mathrm{PTh}$ coating $\mathrm{Ni}$ content was $75 \cdot 1 \pm 1 \cdot 8 \%$ and Mo $20 \cdot 2 \pm 0.7 \%$ (table 1 ). The carbon content was $2.8 \pm 0.9 \%$, sulphur $1.9 \pm 0.9 \%$ (table 1 ). On the basis of the $\mathrm{C}$ and $\mathrm{S}$ content in the coatings the polythiophene content in $\mathrm{Ni}-\mathrm{Mo}+\mathrm{PTh}$ was calculated which was about $4.6 \%$ (table 1 ).

Values of the corrosion parameters were determined from measured dependencies of the $j=f(E)$ behaviour. It was found that for the composite coatings with thiophene the value of the corrosion current is higher and that of the corrosion potential is more positive compared to the corresponding values of the Ni-Mo coatings

Table 1. Corrosion parameters of obtained coatings.

\begin{tabular}{|c|c|c|c|c|}
\hline Type of coatings & $\begin{array}{c}E_{\text {cor }} \\
(\mathrm{mV})\end{array}$ & $\begin{array}{c}R_{\mathrm{p}} \\
\left(\mathrm{kohm} \mathrm{cm}^{2}\right)\end{array}$ & $\begin{array}{c}j_{\text {corr }} \\
\left(\mu \mathrm{A} \mathrm{cm}^{-2}\right)\end{array}$ & $R_{\mathrm{f}}$ \\
\hline $\mathrm{Ni}-\mathrm{Mo}+\mathrm{PTh}$ & -393 & 1.98 & $18 \cdot 8$ & $46 \cdot 7$ \\
\hline $\mathrm{Ni}-\mathrm{Mo}+\mathrm{PE}_{\mathrm{Ni}}$ & -569 & $0 \cdot 82$ & $9 \cdot 6$ & $56 \cdot 1$ \\
\hline
\end{tabular}



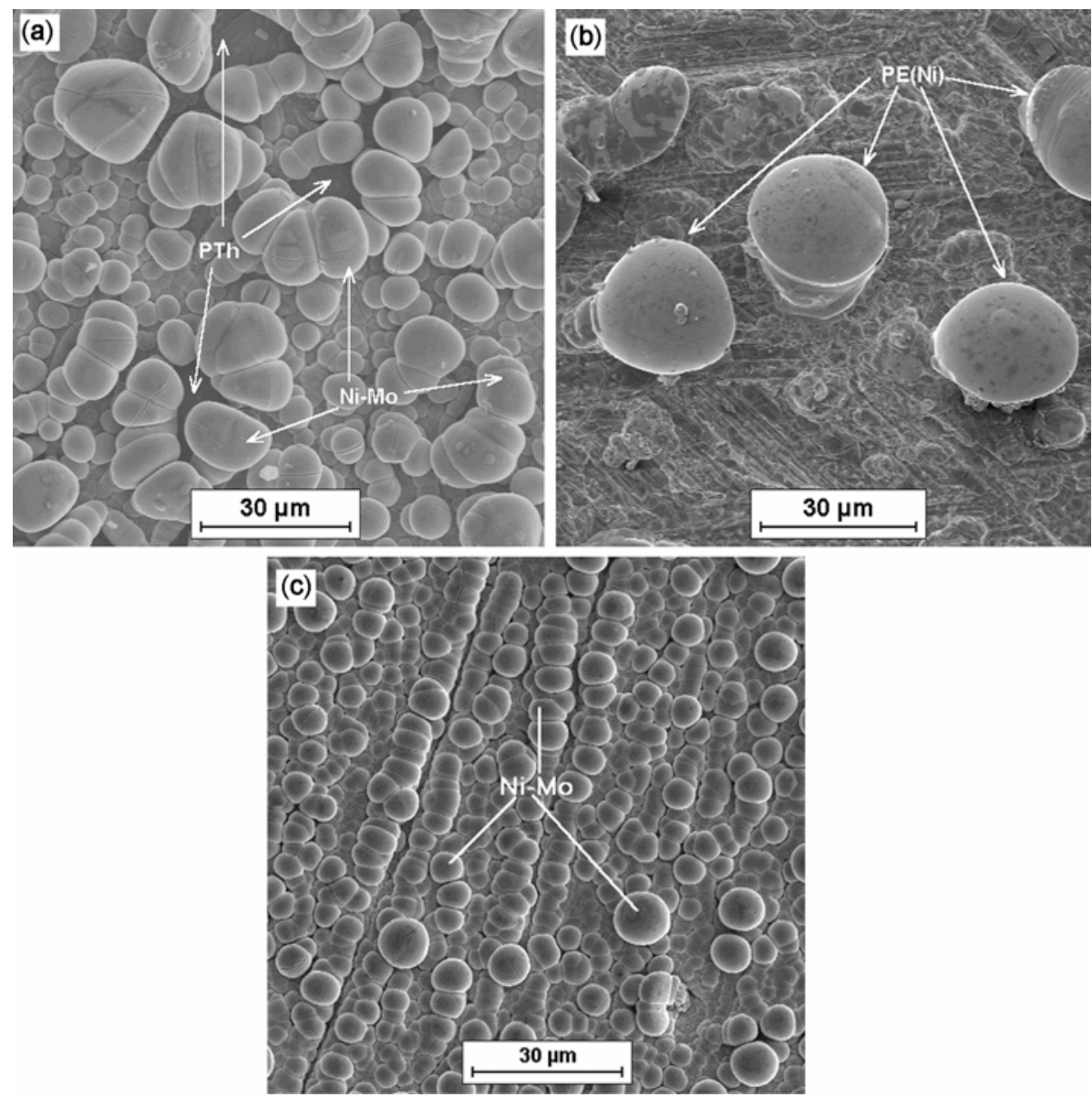

Figure 1. Surface morphology for Ni-Mo + PE (a), Ni-Mo + PTh (b) and Ni-Mo (c) coatings
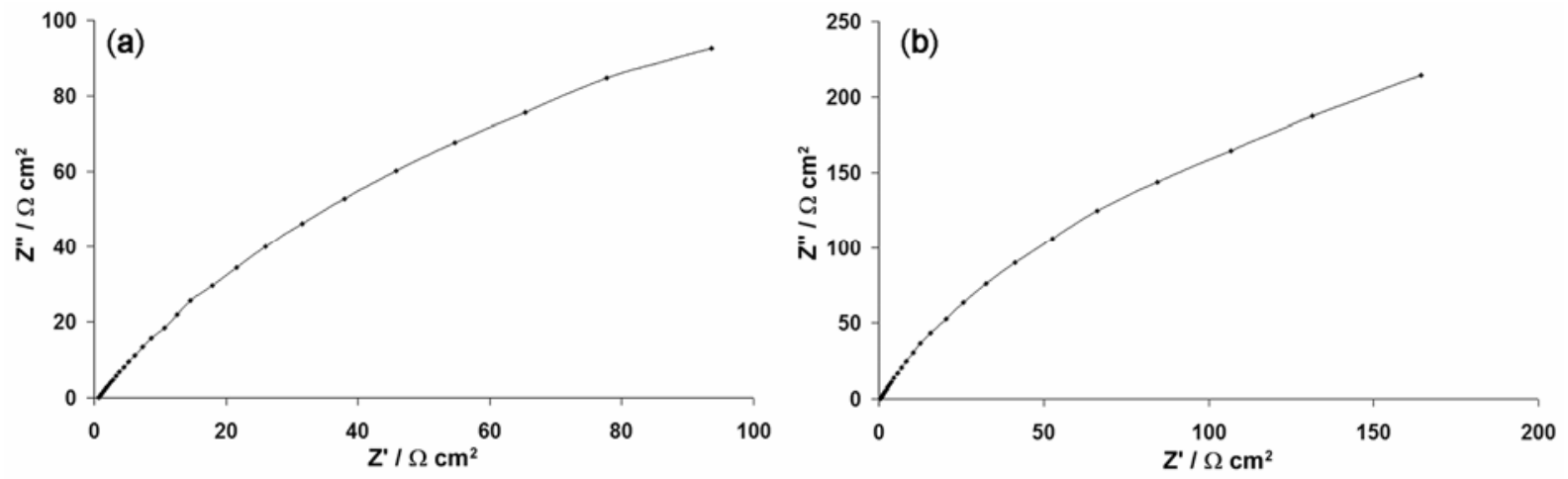

Figure 2. Dependences of $Z^{\prime \prime}=f\left(z^{\prime}\right)$ for the $\mathrm{Ni}-\mathrm{Mo}+\mathrm{PE}(\mathbf{a})$ and $\mathrm{Ni}-\mathrm{Mo}+\mathrm{PTh}(\mathbf{b})$ coatings.

with PE (table 1). This suggests greater resistance of the $\mathrm{Ni}-\mathrm{Mo}+\mathrm{PTh}$ coatings in alkaline solutions. On solid electrodes, a.c. impedance plots deviate from the classical Randles' equivalent circuit. The models for solid electrodes contained a constant phase element (CPE) instead of the double-layer capacitance. The typical model for solid, rough or porous electrodes is the one-constant phase element (CPE 1) (Lasia 2001). The a.c. impedance behaviour of the coatings could be described by the $\mathrm{CPE}$
1 electrode model. This model consists of the solution resistance $R_{s}$ in series with a parallel connection of the CPE element and the polarization resistance $R_{p}$ (KarimiShervedani and Lasia 1999). The impedance data could be analysed using complex non-linear least-squares (CNLS) fitting program (Lasia 2001). As a result of an approximation of the experimental data using the CPE 1 model, the following parameters could be obtained: $R_{s}$, $R_{\mathrm{p}}, T, \phi$, where $T$ is the capacity parameter and $\phi$ is a 
dimensionless parameter related to the rotation of the complex plane plot, $Z_{\mathrm{CPE}}=1 /(j \omega)^{\phi} T$, where $\omega$ is the angular frequency of a.c. voltage. The double-layer capacitance $C_{\mathrm{dl}}$ was calculated according to (1) (KarimiShervedani and Lasia 1999)

$$
T=C_{\mathrm{dl}}^{\phi}\left(1 / R_{\mathrm{s}}+1 / R_{\mathrm{p}}\right)^{(1-\phi)} \text {. }
$$

The ratio of the value $C_{\mathrm{dl}}$ to the capacitance of the ideal smooth surface of electrolytic nickel $\left(20 \mu \mathrm{F} \cdot \mathrm{cm}^{-2}\right.$ (KarimiShervedani and Lasia 1999) gives the value of surface roughness factor, $R_{\mathrm{f}}$. This value for the composite coatings with thiophene is compared to the coatings with PE (table 1). Further evidence for this is the higher value of the polarization resistance $R_{\mathrm{p}}$ for the $\mathrm{Ni}-\mathrm{Mo}+$ PTh coatings, than for the coatings with polyethylene (table 1).

The results of the EIS investigations were analysed in the form Nyquist $\left(Z^{\prime \prime}=f\left(Z^{\prime}\right)\right)$ and Bode $(\log |Z|=f(\log \omega)$ and $\theta=f(\log \omega)$ diagrams, where $|Z|=\left(\left(Z^{\prime}\right)^{2}+\left(Z^{\prime \prime}\right)^{2}\right)^{1 / 2}$ and $\theta=\operatorname{arc}$ tgent $\left(Z^{\prime \prime} / Z^{\prime}\right)$ (figures 2 and 3$)$. These investigations confirmed the diversified characteristic of the impedance components (real $Z^{\prime}$ and imaginary $Z^{\prime \prime}$ ) in the alkaline solution. The Nyquist diagram for the $\mathrm{Ni}-$ $\mathrm{Mo}+\mathrm{PE}$ and Ni-Mo + PTh composite coatings is characterized by a straight line in the whole range of frequencies (suggesting a diffusion mechanism for the corrosion

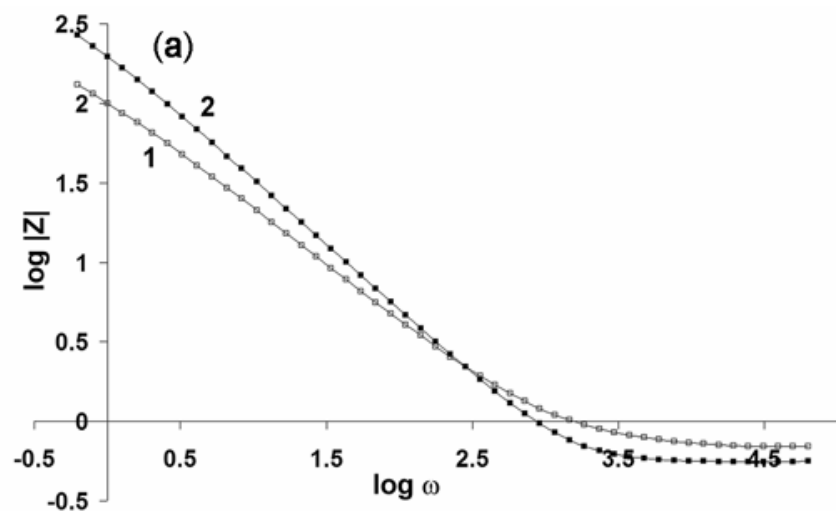

(b)

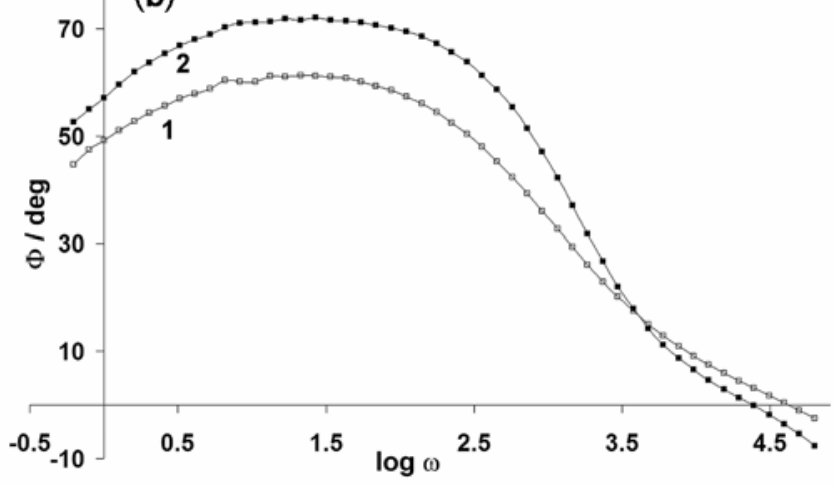

Figure 3. Dependence of $\log |Z|=f(\log \omega)$ : (a) for $\mathrm{Ni}-\mathrm{Mo}+$ $\mathrm{PE}(1), \mathrm{Ni}-\mathrm{Mo}+\mathrm{PTh}(2)$ and $q=f(\log \omega)$ and (b) for Ni$\mathrm{Mo}+\mathrm{PE}(1), \mathrm{Ni}-\mathrm{Mo}+\mathrm{PTh}(2)$. process) (figure 2). It was found that the coatings with PTh are characterized by higher value of the impedance module and phase angle compared with those for the Ni$\mathrm{Mo}+\mathrm{PE}$ coatings (figure 3). Moreover, the dependence $\theta=f(\log \omega)$ for the coatings with PTh show a wider range of independence of the phase angle value from the logarithm of angular frequency compared to the Ni-Mo $+\mathrm{PE}$ coatings. This wider range of independence of $\theta=f$ $(\log \omega)$, implies that the coating is more corrosion resistant.

On the basis of these electrochemical investigations it was found that the coatings with polythiophene are more corrosion resistant in alkaline solution than the coatings with non-conducting, nickel plated PE. It was found that the presence of nickel on the coatings surface decreased the corrosion resistance, because $\mathrm{Ni}$ corrosion resistance is lower than $\mathrm{Ni}-\mathrm{Mo}$ corrosion resistance. The corrosion resistance of coatings with $\mathrm{PTh}$ is enhanced by a decrease in the active surface area.

\section{Conclusions}

It was found that $\mathrm{Ni}-\mathrm{Mo}+\mathrm{PTh}$ coatings are more resistant to corrosion in alkaline solutions than the $\mathrm{Ni}-$ $\mathrm{Mo}+\mathrm{PE}$ coatings. For the coatings with polythiophene a more positive value of the corrosion potential, a lower value of the corrosion current and the surface roughness factor, and also a higher value of the polarization resistance was observed. This is caused by the presence of PTh, which decreased the active surface area. Moreover, parameters determined by the EIS method provide a means for estimating the corrosion resistance of coatings, and confirm the results obtained from potentiodynamic measurements.

\section{References}

Bozzini B and Sgura I 2006 J. Appl. Electrochem. 36 983

Hamid Z A and Ghayad J M 2002 Mat. Letts 53238

Karimi-Shervedani R and Lasia A 1998 J. Electrochem. Soc. 1452219

Karimi-Shervedani R and Lasia A 1999 J. Appl. Electrochem. 29982

Landolt D, Podlaha E J and Zech N 1999 Z. Phys. Chem. 208 167

Lasia A 2001 J. Electroanal. Chem. 30500

Niedbała J 2006 Mater. Sci. Forum 514-516 465

Niedbała J, Budniok A and Lagiewka E 2006 Mater. Sci. Forum 514-516 1176

Niedbała J, Budniok A and Lagiewka E 2008 Thin Solid Films 5166191

Niedbała J, Panek J, Budniok A and Lagiewka E 2004 Kompozyty (Composites) 483

Wang F, Arai S and Endo M 2004 Mat. Trans. 451311 